\title{
INVESTIGACIÓN/RESEARCH
}

\author{
Recibido: 23/04/2015 --- Aceptado: 07/06/2015 --- Publicado: 15/09/2015
}

\section{AUTOREGULACIÓN Y CREATIVIDAD PUBLICITARIA EN EL SECTOR DEL AUTOMÓVIL EN ESPAÑA: FRENO AL TREN VERDE}

Marian Núñez Cansado: Universidad de Valladolid, España

mariannc11@yahoo.es

Luis Rodrigo Martín: Universidad de Valladolid, España

lrodrigo@nmca.uva.es

\section{Resumen}

El abuso de términos ecológicos en el sector motor ha llevado a las instituciones nacionales e internacionales relacionadas con la autorregulación publicitaria a crear Códigos de regulación medioambiental en las comunicaciones comerciales. A pesar de la existencia de nuevas normas de conducta, las grandes marcas de automóvil con impávida actitud, siguen profanando una y otra vez el término ecología, atendiendo a intereses propios y contrarios al del consumidor. Planteamos en este artículo una visión general de la situación actual: haciendo un recorrido por las principales normas de autorregulación, las sentencias existentes hasta el momento, y las campañas infractoras, con el fin de que el lector pueda decidir si la autorregulación ha logrado o no frenar este tren verde.

Palabras clave: Autorregulación, Publicidad, Ética, Creatividad, Medio ambiente, Sector automóvil.

\section{SELF-REGULATIONS AND CREATIVE ADVERTISING IN THE AUTOMOBILE SECTOR IN SPAIN: STOPPING THE GREEN TRAIN}

\begin{abstract}
The abusive use of ecological words in the engine field has led national and international institutions related to advertising self-regulation to come up with environmental regulations codes regarding trading communications. Despite the existence of new behavior standards, the big motor vehicle brands, which have an

\footnotetext{
${ }^{1}$ Marian Nuñez Cansado: Licenciada en Ciencias de la Información, Licenciada en Psicología, Doctora en Comunicación y Sicología. Es profesora Psicología de la Comunicación y Ética y Deontología de la Comunicación en la Universidad de Valladolid mariannc11@yahoo.es
} 
unperturbed attitude, keep on profaning the Word 'ecology again and again. They only bear in mind their own interests, which are against those of the consumer. This article brings up a general view of the present situation and it does it by making a tour through the main self-regulation rules, the so far existing judicial judgments as well as the law-breaking campaigns so that the reader may be able to decide whether self-regulation has succeeded in stopping this green train.

Keywords: Self-Regulation, Advertising, Ethic, Creativity, Environment, Motor Vehicle Field.

\section{Introducción}

\section{1 Valor ecológico en el discurso publicitario}

El empleo de valores en las estrategias publicitarias no es una práctica innovadora. Desde la pre-publicidad hasta la publicidad, sus discursos han supuesto un eficaz diagnostico de los valores sociales y culturales que han imperado en cada época.

Tanto valores colectivos (juventud, modernidad, tecnología, tradición) como valores transitivos (amistad, solidaridad, ecología), bases de campañas publicitarias, han permitido la creación de atribuciones de nuevas simbologías al producto y/o marca que per sé nunca podrían haber encarnado.

Los acontecimientos de 1968 alzaron el valor de la lucha y la juventud. A raíz de entonces Coca-Cola se convirtió en abanderado de este valor social: mensajes paradisíacos, hedonistas y desenvueltos; Marlboro tomó como referencia el valor de libertad e independencia personificado en el ya mítico vaquero, la llegada de la conciencia social de solidaridad llevó a Benetton a mostramos grandes imágenes para la controversia. Así podríamos nombrar una larga lista de marcas asociadas a valores en auge de cada época.

En la última década, según afirma Ronald Inglehart 2, profesor e investigador en el Center for Political Studies (Universidad de Michigan); se ha producido una verdadera "revolución silenciosa" mediante el cambio de valores en los países industrializados. El tránsito de los viejos valores materialistas (altos ingresos, crecimiento, orden, seguridad) hacia valores post-materialistas (participación, equilibrio ecológico...) ha generado importantes consecuencias entre las que se encuentra la aparición de tendencias ecologistas que conllevan la repentina preocupación por el medio ambiente. Tal y como afirma el investigador, los valores son cuasi-axiomas, representan una especie de imperativos a respetar. Los valores no son opcionales, están ahí y forman parte del sistema social.

2 Inglehasrt. R., “Modernización Y Posmodernizacion: El Cambio Cultural, Económico Y Político En 43 Sociedades." Princeton University Press, Princeton, 1997 
El estudio realizado por la World Value Survey ${ }^{3}$ en el año 2000, ya avala las hipótesis sobre el cambio de valores. Ante las variables "cuidado del medio ambiente" o "desarrollo económico" y "creación de puestos de trabajo", en España, un 53,6\% prefirió el cuidado del medio ambiente frente a un 39,2\% que optó por el desarrollo económico y la creación de puestos de trabajo.

Las mujeres optaron en un $56,5 \%$ por la protección del medio ambiente, los hombres en un $50,7 \%$. Las diferencias más significativas se encuentran en el salto generacional de los 20 a los 50 años. En el segmento 15 - 29 años, el 60,5\% prefiere la protección del medio ambiente frente al segmento de más de 50 años, donde el 47,8\% tomaron la elección de la protección del medio ambiente.

Juan Díez Nicolás ${ }^{4}$ catedrático de Sociología en la Universidad Complutense de Madrid, en sus investigaciones más recientes, se plantea el por qué de esta transición de valores. Su respuesta: "uno se atreve a sugerir que el gran éxito de las sociedades industrializadas al conseguir cada vez mayor nivel de vida para grandes grupos de población ha supuesto un deterioro tal del medio ambiente que se ha convertido en una amenaza para la supervivencia de la humanidad. Por tanto, el posmaterialismo, como sistema de valores que da menos importancia al crecimiento económico que a la protección del medio ambiente, es exactamente el sistema de valores necesario para responder a esta nueva situación mundial".

Si el valor "ecología" forma parte del sistema social, sin lugar a dudas, también estará presente en procesos de branding, convirtiéndose en un claro exponente de la máxima expresión del producto o la marca.

Así, en campañas publicitarias del sector motor realizadas en los años 80 era muy común encontrarse apelaciones relacionadas con valores materialistas como la potencia o la velocidad.

"Audi A4, de 0 a 100 en un segundo"

"Alfa 145, suma potencia..."

En los años 90, el valor predominante fue la seguridad:

"Audi A8 ha creado el automóvil más seguro del mundo"

"Alfa 146 TI. Cuanto más potente más seguro"

A partir del año 2000 comenzó la batalla por querer ser y parecer ecológicos:

"El menos contaminante, el que menos $\mathrm{CO}^{2}$ emite,..."

"Audi A8 Hybrid: Lujo ecológico sobre ruedas"

"Wolkswagen: Reduce lo que puedas, compensa lo que no puedas"

"Opel: verde, más verde, ecoflex"

Según el estudio publicado por la revista Environment and Behavior "Experiencias emocionales relacionadas con la naturaleza" obra de los investigadores Hartmann,

\footnotetext{
$3 \quad$ World Valuessurvey Association. Disponible en :http://www.worldvaluessurvey.org/. Consultado el 30 de Enero de 2015
}

$4 \quad$ World Valuessurvey Association. Disponible en:

http://www.worldvaluessurvey.org/Upload/5_Soc-Pos-Inf-Post.pdf. consultado el día 30 de enero de 2015 
Patrick; Apaolaza Ibáñez, Vanessa (2008)5, las imágenes de una "naturaleza virtual" de bosques, costas y cascadas que las personas perciben en los medios de comunicación reflejan el deseo de experimentar o vivir la naturaleza y obtener los "beneficios psicológicos" de interactuar con el medio ambiente. El consumo de productos verdes es así el sustitutivo del "verdadero" contacto con la naturaleza. Así imágenes y textos con motivos naturales empleados para promocionar una marca tienen "una influencia positiva y significativa en el constructo de la actitud", crear marcas verdes es positivo para la empresa, para el medio ambiente y consecuentemente para el receptor.

\section{OBJETIVOS}

La identificación de productos y marcas con cualquier elemento que reviva este valor será valorado positivamente por el sujeto receptor que estrechará unos intensos lazos emocionales coherentes con su modelo de sociedad y sus valores.

Según un estudio realizado por 6thdimensión, un 65\% de españoles estarían dispuestos a pagar más por productos que no dañen al medio ambiente. EL 56 \% estaría dispuesto a pagar más impuestos si eso ayudara a conservar mejor el medio ambiente.

Dos aspectos definitorios en la apelación "verde" confluyen en este nuevo valor posmaterialista: de un lado, la defensa del medio ambiente lleva al rechazo de aquellas marcas o productos que contribuyan (con sus sistemas de producción, de distribución consumo, eliminación de sus residuos, etc.) al deterioro del medio ambiente y de otro lado, la aceptación absoluta, e identificación con aquellas que muestren esfuerzos por la conservación del medio ambiente. Se trata en definitiva de provocar un cambio de actitud mediante la asociación de este valor con nuestros productos.

\section{METODOLOGÍA}

La investigación aporta una visión general de la situación actual, reflexiona y contribuye: haciendo un recorrido por las principales normas de autorregulación, las sentencias existentes hasta el momento, y las campañas infractoras, con el fin de que el lector pueda decidir si la autorregulación ha logrado o no frenar este tren verde.

\section{DISCUSIÓN}

El automóvil es por definición un producto anti ecológico, por lo que puede producir, atendiendo a este nuevo valor social, un claro rechazo. Contrarrestar esta situación utilizando reclamos verdes, de forma implícita o explícita, puede convertir

\footnotetext{
5 Hartmann, Patrick; Apaolaza Ibáñez, Vanessa (2008) “Virtual nature experiences as emotional benefits in green product consumption: the moderating role of environmental attitudes" Environment and Behavior, 40 (6)
} 
a una marca de este sector, potencialmente rechazable, en un producto totalmente aceptado por el mercado.

Nada hay de deshonesto en recurrir a reclamos verdes sobre beneficios del producto o servicio. Durante la historia de la publicidad es común la creación del branding emocional utilizando los valores imperantes en la sociedad. El verdadero problema comienza cuando la utilización de estos valores puede confundir, engañar y perjudicar directamente a la sociedad. Cuando la creación de simbolismos conduce a la falta de honestidad, veracidad y de respeto al buen gusto y a la buena fe del consumidor, llegados a este punto podemos afirmar que no se está realizando un buen uso de los valores sociales imperantes en la sociedad.

Fue el ecologista neoyorquino Jay Westerveld el primero en usar el término "greenwashing" para referirse, en la década de los 80, a cadenas de hoteles que utilizaban reclamos ecológicos para atraer una clientela que comenzaba a surgir como consecuencia de una nueva actividad de ocio: el turismo ecológico. Estas cadenas promovían la reutilización de toallas pero, sin embargo, carecían de estrategias de reciclaje definidas.

El "greenwashing" o engaño verde (ecológico) es definido como "el acto de inducir a error a los consumidores en relación con las prácticas ambientales de una empresa o los beneficios ambientales de un producto o servicio".

Esta prolífera actividad publicitaria consiste en la utilización del reclamo medioambiental con el único fin de limpiar la imagen de empresas que normalmente son causantes de gran parte de la contaminación o deterioro medioambiental. Su objetivo podría resumirse en el clásico refrán: "si no puedes con tu enemigo, únete a él". Tratan de paliar así el rechazo que a priori pudieran producir, convirtiendo a las marcas en abanderadas del valor ecológico, gracias a afirmaciones que a menudo poco o nada tienen que ver con la realidad.

Tras este auge pro-naturaleza, y ante el flagrante engaño que suponía para el consumidor, las principales asociaciones de autorregulación europea se hicieron eco de la problemática de discursos verdes engañosos, tratando de minimizar los daños mediante la creación de códigos que regulasen estas prácticas.

El 15 de octubre de 2007, el pueblo noruego tomó la determinación de regular la utilización de términos como; "limpio", "ecológico" o "verde", "amistosos con el medio ambiente", en la comunicación comercial de vehículos considerando que la utilización de estos términos de manera ambigua y poco precisa constituía un hecho de publicidad engañosa que atacaba directamente a los valores del medio ambiente.

En octubre de ese mismo año, la Unión de Consumidores de España-UCE6 ${ }^{\circ}$ solicitó al Ministerio de Industria la prohibición de utilizar los términos verde, ecológico o limpio en la publicidad asociada a vehículos, sin respuesta por parte de las autoridades pertinentes

\footnotetext{
$6 \quad$ Unión de Consumidores de España. consultado en 12 de enero de 2014, disponible en: ttp://www.consumidors.org/UserFiles/File/PDF\%20Altres\%20entittats/Nota\%20de\%20prensa_Pub licidad\%20coches\%20ecologicos.pdf
} 
En el EASA ANUAL REVIEW de 2007, la Asociación Europea en un breve artículo, pide la responsabilidad hacia el medio ambiente, exigiendo que las declaraciones ambientales se basen en pruebas demostrables y ventajas reales.

En el año 2008, los representantes de EASA se reúnen con representantes de la DG ENV y la DG SANCO, para establecer conversaciones acerca de la autorregulación publicitaria de las reclamaciones verdes. EASA considera imprescindible formar a los jurados sobre conocimientos técnicos necesarios para pronunciarse sobre la falsedad o veracidad de este tipo de reclamaciones. Un año después, en el año 2009, todavía no existía una regulación internacional.

EASA reclama a la Cámara Internacional de Comercio la necesidad de autorregulación de este tipo de prácticas mediante la inclusión, en el Código de Prácticas Publicitarias y Mercadotecnia, de un capítulo que garantice la confianza del consumidor ante las afirmaciones realizadas por la industria del motor, ya que no sólo se estaba induciendo a error al consumidor respecto a determinadas marcas, sino que empezábamos a correr el riesgo de perder la eficacia ante el valor de las campañas comprometidas realmente con el medio ambiente y necesarias para luchar contra el calentamiento global.

En 2009, en España, el Ministerio de Medio Ambiente acordó con las empresas de automoción, del medio rural y marino, del sector energético y Autocontrol, la firma del un Código de Autorregulación: "Código de autorregulación sobre argumentos ambientales en comunicaciones comerciales" 7 , que trata de frenar la avalancha de argumentaciones verdes en este sector.

Diecinueve empresas se sumarán a la iniciativa aceptando y comprometiéndose con el nuevo Código de Autorregulación. Por parte del sector energético se adhirieron al compromiso: Cepsa, Repsol, Acciona, Endesa, Iberdrola y Gas Natural/Unión Fenosa. La empresas de sector motor firmantes constituyen casi un $95 \%$ del total de las industrias presentes en nuestro país: Kia, Chrysler, CitroPeugeot, Renault, Seat, Grupo Volkswagen (Volkswagen, Audi y Skoda) Ford, Toyota y Lexus, Honda, General Motors (Opel y Saab), Chevrolet y Fiat.

El nuevo código no prohíbe la utilización de argumentaciones medio ambientales, sino que establece una serie de restricciones en su uso, exigiendo argumentos responsables, veraces, precisos y verificables.

Aportará también una serie de directrices para el uso de adjetivos asociados con el medio ambiente tales como: "no dañino para el medio ambiente", "verde", "ecológico", "sostenible", "compostable", "degradable", "reciclable", "reutilizable", "reciclado", "consumo reducido de energía", "ecológico", los cuales deberán evitarse o justificarse mediante acotaciones claras, notorias y fácilmente entendibles.

En el año 2010, ante las presiones constantes de Europa y el prolífero número de discursos publicitarios con reclamaciones verdes engañosas, la Cámara Internacional de Comercio opta por incluir un capítulo completo, en su Código de Prácticas

7 Autocontrol. Códigos. Disponible en :

http://www.autocontrol.es/pdfs/pdfs_codigos/CODMEDIOAMBIENTE.pdf.Consultado el día 25

de febrero de 2015 
Publicitarias y Mercadotecnia, acerca de la autorregulación sobre las aseveraciones de naturaleza ambiental en comunicaciones comerciales: Capítulo E ${ }^{8}$.

Este capítulo responde a las reclamaciones realizadas por EASA en materias de formación medioambiental, ya que incluye una tabla de conceptos relevantes junto con las interpretaciones actuales sobre temas de marketing ambiental, y a las reclamaciones de asociaciones de usuarios y medioambientales, solicitando un freno a las prácticas de greenwashing.

Según EASA ${ }^{9}$, todas las comunicaciones de marketing deben ser juzgadas por su posible impacto en el consumidor razonable, teniendo en cuenta las características del grupo objetivo y el medio utilizado. La interpretación de un consumidor de un reclamo verde se ve afectado por el contexto en el que se presenta, el nivel de conocimientos y experiencias, y la forma en que se transmite. Por lo tanto, un reclamo verde que es científicamente exacto, podría ser engañoso si su comprensión pude dar lugar a malos entendidos, tanto por omisión como por acción. Además, los consumidores razonables pueden tener diferentes interpretaciones de una denuncia presentada en un contexto particular. La publicidad de los aspectos ambientales de un producto requiere a menudo de clarificación y una explicación adicional, no sólo el uso de palabras de trending para atraer a los consumidores. Como resultado, el uso afirmaciones ecológicas es una tarea más compleja que requiere de legislación más explícita y concreta.

El capítulo del Código de Prácticas Publicitarias, de la Cámara Internacional de Comercio, regula los discursos publicitarios que hacen referencia a aspectos ambientales o ecológicos relativos a la producción, empaque, distribución, uso/consumo o disposición de productos, y bajo cualquier medio, incluyendo etiquetado, inserciones en packagings, materiales promocionales y en puntos de venta, literatura del producto, así como vía telefónica, digital o medios electrónicos tales como correo electrónico e Internet.

Del mismo modo que el Código de Autorregulación Español, este Código Internacional, hace una clara alusión a los adjetivos asociados con el medio ambiente y a la necesidad de que vayan acompañados de afirmaciones demostrables y veraces. Las cifras presentadas en los informes anuales de EASA ${ }^{10}$ son alarmantes; del total de las reclamaciones realizadas en el año 2009 un 2,7\% estaban relacionadas con infracciones contra el medio ambiente. En el año 2010 aumentaron hasta un 21\%, siendo la industria del motor la segunda con más infracciones tan sólo a un puesto del sector energía.

8 Cámara Internacional de Comercio. Código de Prácticas Publicitarias. Disponible en: http://www.iccwbo.org/uploadedFiles/ICC/policy/marketing/Statements/Spanish\%20ICC\%20Co nsolidated \%20Code\%20on\%20MA\%20Practice.pdf. Consultado el 19 de marzo de 2015

$9 \quad$ European Advertising Standards Alliance. Nota de prensa. Disponible en: http://www.easaalliance.org/Search/page.aspx/18?sRequest=capitulo\%20E. Consultado en día 2 de Febrero de 2015.

10 European Advertising Standards Alliance. Informes 2009. Disponible en http://www.easaalliance.org/Publications/Statistics/page.aspx/375. Consultado el 20 de diciembre de 2014. 
Las cifras hablan por sí solas, aunque tal vez, debiéramos ser cautos a la hora de analizar este dato, quizás no representa un aumento de anuncios infractores, sino más bien un aumento de sensibilidad por parte de los usuarios, ya que el $80 \%$ de las reclamaciones realizadas durante este año fueron hechas por los receptores y/o asociaciones de usuarios. Podemos inferir el aumento de conciencia medioambiental, que convierte a los usuarios en fieles vigilantes de la publicidad frente a falsas alegaciones ecológicas.

\subsection{Un claro ejemplo de Greenwashing: sector del automóvil}

Clasificaremos en tres grupos los "pecados verdes" más comunes cometidos por la publicidad en el sector automovilístico:

1. Incitación a conductas inapropiadas: incitar a acciones que conllevan el deterioro y la degradación de espacios naturales mostrando un desprecio absoluto por la naturaleza.

2. Términos vagos e imprecisos: utilización de términos relacionados con el medio ambiente de forma vaga e imprecisa, abusando de afirmaciones que esgrimen continuas reivindicaciones medioambientales que en ningún caso suponen un beneficio real.

3. Compensación oculta: empresas que utilizan campañas de responsabilidad social en las que se apuesta por la causa ambiental, minimizando ante el consumidor las consecuencias reales del impacto medioambiental, con el único fin de tergiversar la percepción de la marca respecto a las prácticas habituales llevadas a cabo por estas empresas relacionadas con la inestabilidad medioambiental.

\subsection{Incitación a conductas inapropiadas}

Quizás sea el "pecado verde" más antiguo y que más comúnmente ha sido infringido por mensajes publicitarios de turismos, en especial por aquellos vehículos conocidos como "todoterrenos" o " $4 \times 4$ ".

En los años 80 y 90 era muy común encontrarnos con discursos publicitarios que giraban en torno al eje naturaleza. La argumentación más recurrente consistía en presentar vehículos de esta categoría circulando brutalmente por espacios naturales: atravesando ríos cristalinos, culminando cumbres inhóspitas, alcanzando lugares inaccesibles; imágenes aderezadas con claims que invitaban a disfrutar de valores como la libertad, la exclusividad o la aventura.

“Suzuki Gran Vitara por su excelente comportamiento en los terrenos más insólitos. De lo que he visto en el monte es lo que más me ha impactado" Suzuki culminando la cumbre de un monte.

"Volvo Cross Country. Hay una clase de personas que piensa que la aventura y el placer de conducir son una misma cosa" Volvo Cross atravesando un río salvaje inmerso en un paraje natural.

"Jeep Cherokee: en la cubre del éxito". Culminando la cumbre de una montaña.

"Jeep Cherokee: hasta en los territorios más salvajes del mundo". Inmerso en un paraje selvático. 
“Donde le lleve un Mitsubishi Montero hace mucho tiempo que no ha llegado nadie". Vehículo zambullido en un paraje natural impenetrable.

"Nissan Terrano II la naturaleza selecciona a los que se adaptan mejor al medio". Vehículo camuflado en la Selva amazónica.

"Land Rover Freelander: Placentera sensación de libertad". Sumido en la sabana africana.

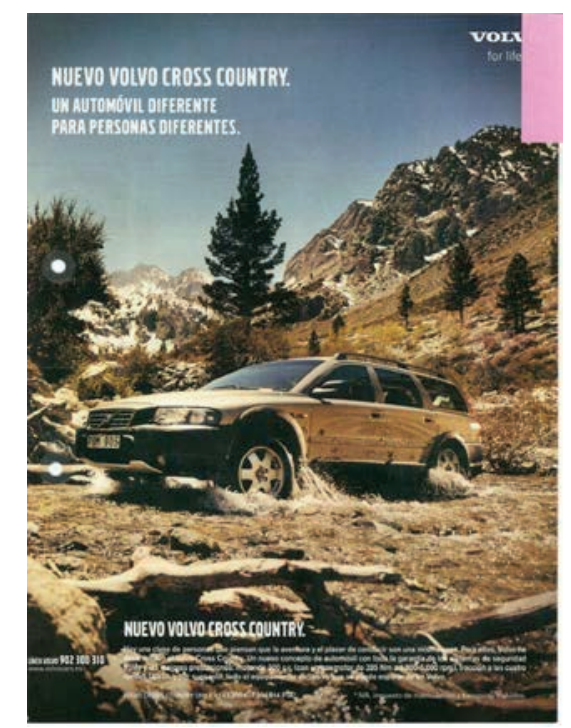

Foto1. Campaña de Volvo Cross

En definitiva, imágenes que nos incitan a circular libremente con estos vehículos por la naturaleza con la promesa de encontrar libertad, aventura, evasión.

El mensaje es evidente: utilizar los vehículos en medios naturales no es perjudicial, es una práctica aceptada y acertada. Este tipo de praxis es una clara invitación al uso no racional e irrespetuoso de la naturaleza que conlleva graves perjuicios.

Este tipo de prácticas, realizadas de forma negligente puede ocasionar deterioro en el suelo, degradación y compactación, que pueden llegar a generar una menor permeabilidad y disminución de la capacidad de absorción del agua y el aire, alterando el ciclo natural de plantas y de animales: la tracción daña la micro fauna (hongos, zooplancton), el rodamiento aplasta vegetales, acelera la disminución de la diversidad y de la cubierta vegetal, afecta a las pistas de olor que dejan los animales, delimitan su territorio, provocan contaminación acústica, contaminación ambiental, partículas de desgaste de neumáticos, etc.

Circular con vehículos $4 \times 4$, ya sean camionetas, jeeps, cuatriciclos y/o motos enduro entre otros, causan daños a la naturaleza aún tomando las precauciones pertinentes. Por más cuidado que tengan los usuarios de este tipo de vehículos, el impacto que se infringe al ambiente es severo.

Ante esta práctica extendida durante la década de los 90, se impone la necesidad de establecer normas que limiten la aparición de los vehículos en espacios naturales. Comienzan a legislarse el tránsito del vehículo en los montes, se limita la circulación de vehículos a motor todo camino que no sea una carretera de la red del Estado. (Ley 
3/95 de 23 de marzo de vías pecuarias, Ley 33/2003 del Patrimonio de las administraciones Públicas...)

Impera la necesidad de transmitir al receptor un cambio de conducta en pos del medio ambiente. A pesar de la riada de discursos perjudiciales, sólo se produjeron dos reclamaciones ante Autocontrol en base al la norma 12 del Código General de Conducta Publicitaria: "Respeto al medio ambiente: La publicidad no incitará ni alentará comportamientos que perjudiquen el medio ambiente."11

En el año 2006 llegará la primera reclamación. Será en esta ocasión un particular el que realice el requerimiento a la marca Volkswagen - Audi España por la publicidad de su vehículo Volkswagen Tuareg. El reclamante alega que el vehículo circula brutalmente entre la naturaleza destrozando caminos y degradando el lecho de un río, compitiendo con un salmón que intentaba remontarle $y$, en definitiva, erosionando un espacio natural. Solicita la retirada del anuncio basándose en una infracción de la norma 12 del Código General de Conducta Publicitaria.

Tal y como se expresa en la sentencia el argumento del anuncio podríamos resumirlo de la siguiente forma:

"Circulando por una carretera entre montañas. En un momento, toma un desvío, introduciéndose en plena naturaleza. El vehículo avanza por un camino de tierra y grava, salvando los desniveles del terreno, tomando curvas e incluso atravesando charcos de agua. En la parte inferior de la pantalla se puede leer: "imágenes rodadas por especialistas en caminos rurales aptos para la circulación". En su camino, el vehículo se detiene mientras está cruzando un río. Mientras escuchamos el caudal de agua corriendo, se muestra un primer plano de una de las ruedas traseras, que está en el agua. Por corte, aparece la imagen de un salmón intentando avanzar a contracorriente por el fondo pedregoso del río. Una vez el salmón sale de pantalla, volvemos a la imagen del vehículo que emprende la marcha para salir del río."

La marca Volkswagen arguyó en su defensa que su anuncio incluía un scroll que rezaba: "imágenes rodadas por especialista en caminos rurales aptos para la circulación" 12 Así, el anuncio en modo alguno reflejaría escenas o conductas absolutamente contrarias al medio ambiente y, por lo tanto, no incitaría a comportamientos perjudiciales para el mismo.

El jurado de Autocontrol en su resolución instó a la rectificación de la leyenda, que consideraban era prácticamente imperceptible por el receptor, por el tamaño y el tiempo de permanencia en pantalla. La leyenda debería aumentarse de tamaño para que el mensaje llegara de forma clara al receptor.

Este fue un dictamen que podríamos tachar de benévolo basándonos en la norma $\mathrm{n}^{\circ} 3$ del Código General de Conductas sobre la interpretación de anuncios:

11 Autoncontrol. Códigos. Disponioble en:

http://www.autocontrol.es/pdfs/Cod_conducta_publicitaria.pdf. Recuperado en día 20 de marzo de 2015.

12 Autocontrol. Sentencias. Disponible en:

http://www.autocontrol.es/panelcontrol/web/paghtml/download.asp?file=rest0774.pdf\&type=rest \&year=2006. Recuperado el 17 de marzo de 2015. 
“3.1.- Los anuncios y las expresiones publicitarias deben ser analizadas en su conjunto, sin descomponer sus partes integrantes y atendiendo a la impresión global que generen en sus destinatarios.

3.2.- No obstante lo anterior, podrán ser objeto de análisis específico aquellas partes que, por aparecer de forma especialmente destacada, capten principalmente la atención del consumidor.

3.3.- En todo caso, cuando un anuncio contenga un mensaje claramente destacado en el sentido del párrafo anterior, el anunciante deberá adoptar las medidas necesarias para que las restantes partes del anuncio sean claramente comprensibles y no introduzcan ni modificaciones ni limitaciones relevantes del mensaje principal" (Código General de Autorregulación Publicitaria. Autocontrol)

Evidentemente existe una disparidad entre el escenario que muestra el anuncio y el scroll, en el que posiblemente, y muy a pesar de su rectificación, pocos receptores reparan. La falta de información o desconocimiento del consumidor pueden conllevar a la incitación de comportamientos que perjudiquen a espacios naturales. La interpretación global del anuncio es una clara incitación a invadir terrenos naturales sin ningún tipo de escrúpulo. ¿Un río puede formar parte de un camino rural apto para el tránsito de vehículos? ¿Acaso sería lícito mostrar imágenes violentas o escenas pornográficas con un scroll que rezara: "no seáis malos esto no es real"?

Del año 2007 data la segunda de las reclamaciones realizadas también por un particular, en esta ocasión contra una publicidad de la que era responsable la entidad Nissan Iberia, S.A ${ }^{13}$.

El anuncio comienza con un vehículo Nissan Pathfinder circulando por un área abrupta que se adentra en una especie de lago donde se transforma en un caimán. Sale del lago y recupera la forma de vehículo, ahora del modelo Nissan Navara, y circula por una zona desértica rocosa transformándose nuevamente, esta vez en una especie de gran serpiente. Finalmente, se muestra el vehículo modelo Nissan Murano circulando por una carretera. Una voz en off cierra el anuncio con la frase: "Nissan $4 \times 4$. Capacidades sin límites". De nuevo una leyenda: "anuncio rodado en circuito cerrado o pistas forestales aptas para la circulación". En esta ocasión, la leyenda era perfectamente perceptible y legible por el receptor, por lo que la causa fue desestimada. No consta en los archivos de Autocontrol ninguna otra sentencia al respecto, ni aceptada ni desestimada.

La necesidad de cubrir nuevos nichos y de generar nuevas ventajas frente a la competencia, hicieron dar un giro a los discursos publicitarios de estos productos. Siguiendo claras estrategias de marketing, los vehículos todoterrenos pasaron a formar parte del paisaje urbano: "Hay pocas cosas de campo que se adapten tan bien a la ciudad": Mitsubishi Montero. Este nuevo giro estratégico llevó a las marcas a

13 Autocontrol. Sentencias. Disponible en:

http:/ / www.autocontrol.es/panelcontrol/web/paghtml/download.asp?file=rest0662.pdf\&type=rest $\underline{\text { \&year }=2005}$. Recuperado en día 20 de marzo de 2015 
suplir los espacios naturales por espacios urbanos, frenando así la fiebre del abuso de escenarios naturales.

A pesar de este giro y presentando total impunidad seguimos encontrando anuncios donde los vehículos irrumpen en espacios naturales inaccesibles y donde fomentan comportamientos irrespetuosos con el medio ambiente. Este es el caso de la campaña lanzada por Renault en el año 2008 (Imagen 2). Nos presentan la imagen de un vehículo invadiendo un bello paisaje con el apoyo de la marca por excelencia de los aventureros: Coronel Tapioca, y por supuesto, sin leyenda.

La campaña de Toyota Land Cruiser en el 2010, (imagen 3) donde el vehículo, ajeno a los daños que ocasiona a la flora y fauna que habita en el río, circula mostrando su habilidad para llegar hasta los lugares más inaccesibles.

La campaña de Mini (imagen 4) donde directamente se insta al receptor: "ve por el mal camino". O las últimas campañas realizadas por la marca Jeep durante este año, 2015, en las que recorrer los montes supone una tarea fácil y recomendable para los usuarios de sus vehículos, incluso podemos encontrar un bosque convertido en garaje ${ }^{14}$. (Imagen 5)

Quizás el receptor se ha habituado tanto a estas imágenes, con el peligro que esto conlleva, que ni tan siquiera percibe la infracción contra el medio ambiente.
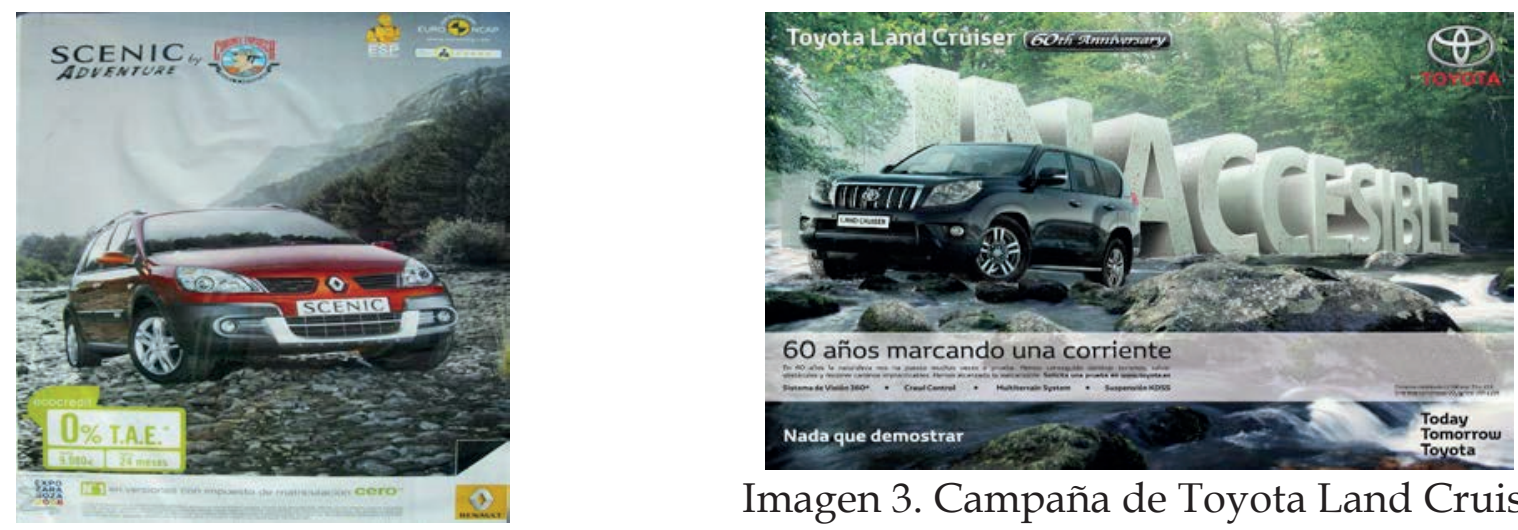

Imagen 3. Campaña de Toyota Land Cruise.

Imagen 2. Campaña de Renault Scen

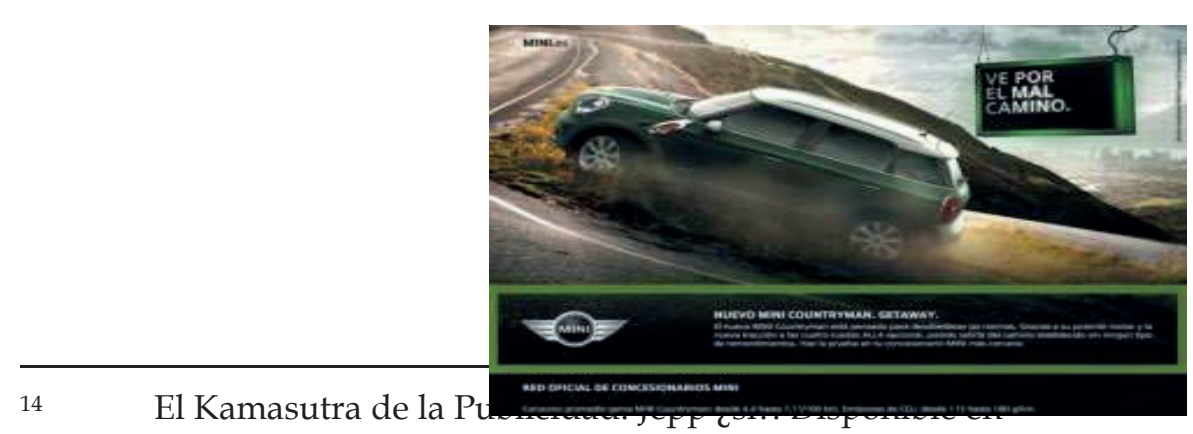

https:/ / elkamasutradelapublicidad.wordpress.com/2013/09/17/jeepsi/https:/ / elkamasutradelapub licidad.wordpress.com/2013/09/17/jeepsi/. Recuperado el día 12 de enero de 2015. 
Imagen 4. Campaña Mini

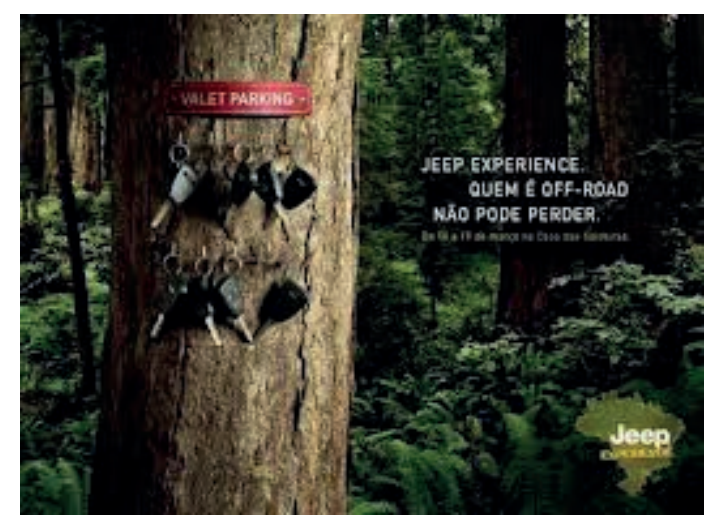

Imagen 5. Campaña de Jepp.

\subsection{Términos vagos e imprecisos}

Según un informe de la Agencia Europea del Medio Ambiente, el transporte por carretera es el responsable del $21 \%$ de las emisiones de gases de efecto invernadero en la UE. La contaminación atmosférica y la emisión de $\mathrm{CO}^{2}$, emitidas por los vehículos tradicionales, o las emisiones de monóxido de carbono, óxido de nitrógeno, hidrocarburos no quemados y otras partículas, emitidas por los coches híbridos, incluso la producción de energía (la mayor parte de ella no renovable) necesaria para los vehículos eléctricos, convierten por definición a la industria del motor en poco o nada ecológica. Podemos afirmar tajantemente que los coches ecológicos no existen. A pesar de ello, y con gran insistencia en los últimos años, la industria del motor trata de rehacer su imagen mediante campañas que muestran su compromiso social con el respeto al medio ambiente. El tándem vehículo - ecología se ha convertido en la última década en el leitmotiv de la publicidad de este sector.

Tan sólo tenemos que echar un vistazo al naming de los turismos, para percatarnos de esta "fiebre verde": Opel Ecoflex, Seat Ecomotive y Ecofriends, Toyota Ecopotencia, Peugeot Ecocup, Renault Eco, Chevrolet Ecotec, Nissan Eco T100, Volkswagen Ecoracer, Ford Focus Econetic... Todas estas composiciones suelen ir aderezadas de imágenes de espacios naturales limpios de contaminación.

El receptor poco ducho en la materia, ante claims tales como: "Disfruta al máximo de la naturaleza y acusa el mínimo impacto: Peugeot Ecocup" o "Más allá del asfalto, todo lo que uno necesita para disfrutar al máximo de la naturaleza: Seat Ecomotive", 
puede concluir que su conducción contribuye a la mejora del medio ambiente, ya que conduce un vehículo ecológico. La identificación, respeto a la naturaleza conducción queda asegurada, olvidando de esta manera el verdadero papel de los vehículos en el efecto invernadero.

La estrategia es sencilla: utilización de términos ambiguos y poco precisos asociados con el medio ambiente, preferentemente el término "ECO", coligados a una promesa de responsabilidad social y aderezado de imágenes de espacios naturales junto a un claim donde se invita a disfrutar de espacios naturales. La diferencia entre esta tipología de anuncios y los nombrados anteriormente es que los vehículos no circulan atravesando espacios naturales, sino que lo utilizan como escenarios secundarios. Los vehículos ruedan por carreteras inmersas en espacios verdes de gran belleza, impregnándose de las características propias de estos ambientes.

Detrás de esta estrategia de marketing nos encontramos que estas declaraciones a favor del medio ambiente consisten en mínimas reducciones de $\mathrm{CO} 2$, sin tener en cuenta que, el hecho de que un vehículo emita menos dióxido de carbono, no le convierte en un coche ecológico, pues siguen produciendo un impacto medio ambiental muy preocupante, con índices que son claros responsables de la contaminación atmosférica.

Es así como esta "excelencia ecológica" (la reducción de $\mathrm{CO}^{2}$ ), ha sido convertida por las grandes marcas de coches en una ventaja frente a su competencia, presentándolos como alternativas ecológicas y dotándoles de cualidades ambientales inexistentes y finalmente causando un claro engaño al receptor e impulsando comportamientos que pueden ser contraproducentes para la causa medioambiental.

Si el consumidor considera que la utilización del vehículo causa un mínimo impacto en el medio ambiente puesto que tiene un vehículo ecológico, lejos de plantearse alternativas imprescindibles para acabar con la contaminación actual, hará uso masivo del vehículo, logrando así incentivar un comportamiento que puede acarrear consecuencias negativas poco favorables.

Otra de las falacias más comunes es convertir una obligación en una clara ventaja sobre la competencia. EL real decreto 837/2002, transposición directiva 1999/94/CE, regula la obligación de informar sobre el $\mathrm{CO}^{2}$ que emiten los vehículos. Esta directiva establece que la información sobre niveles de emisiones de $\mathrm{CO}^{2}$ y el ahorro de combustible se debe exhibir en puntos de venta y en publicaciones de promoción de turismos. En muchas ocasiones estas emisiones son utilizadas estratégicamente por las marcas, explotando la falta de conocimiento de los consumidores en esta materia, ya que la proximidad de los término "consumo de $\mathrm{CO}^{2}$ " y "eco" pueden llegar a la fusión de ambos conceptos, propiciando inferencias falsas sobre las facultades ecológicas de ese vehículo, aún cuando la realidad es que sus emisiones son iguales o mayores que las de la competencia. De esta forma, la marca reduce el impacto negativo del producto y le otorga una clara ventaja a favor de la causa social. En el año 2007, la marca Renault lanza su campaña publicitaria para promocionar la etiqueta $\mathrm{Eco}^{2}$ (Imagen 6) de algunos de sus automóviles. La promesa en el discurso se basa en promocionar su nueva gama de vehículos más económicos y más ecológicos, capaces de contribuir con la disminución de la contaminación atmosférica. Pero... 
¿qué tiene de ecológico un coche que emite más de 200 gramos de CO2 cada kilómetro?

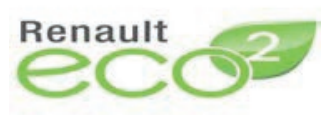

Imagen 6. Logotipo de Renault Eco²

Lejos de aportar un beneficio real al medio ambiente, ninguno de los vehículos anunciados como supuestamente ecológicos, se encontraba dentro de los vehículos menos contaminantes del mercado (según un estudio realizado por el RACC Automóvil Club junto con la Fia Foundation y el club alemán ADAC ${ }^{15}$ ) siendo uno de sus modelos, el Renault Grand Space 3.0 dCi, el segundo más contaminante.

Con la argumentación esgrimida en sus campañas: "Todos queremos un coche ecológico", "porque todos tenemos corazoncito, ecología Renault ecología al alcance de todos", "paga menos por ser ecológico desde hoy" dan un giro a la responsabilidad social del usuario, inculpando del efecto invernadero a aquellos que no consumen sus productos.

A Renault le seguirán otras muchas marcas como Seat Ecomotive:"gasta menos y es respetuosos con el medio ambiente" (Seat Ibiza y Altea).

A pesar de este panorama, durante los años 2007/2008, Autocontrol no recibe ninguna reclamación al respecto, y las marcas arguyen ventajas ecológicas sin ninguna restricción.

Las sanciones llegaron en España en el año 2011. Dos fueron las reclamaciones presentadas en Autocontrol y resueltas mediante la aplicación del Código de Autorregulación sobre Argumentos Ambientales en Comunicaciones Comerciales ${ }^{16}$. La primera data del 26 de mayo de 2011, en la cual el jurado estima la reclamación presentada por la Asociación de Amigos de la Tierra contra una publicidad de la que era responsable Honda Automóviles España, S.A. (Imagen 7). Según el jurado, el anuncio vulneraba la norma 11 del código17: "las aseveraciones genéricas o no específicas sobre beneficios de tipo ambiental, en particular aseveraciones tales como "no dañino para el medio ambiente", "verde", "ecológico", "sostenible", deben evitarse o justificarse mediante acotaciones. Las acotaciones deben ser claras, notorias

15 RACC Automóvil Club. Dossier de Prensa. Disponible en:

http://imagenes.w3.racc.es/uploads/file/2566_NP_ecotest_fase_1_2003.pdf. Recuperado el 14 de abril de 2003.

16 Autocontrol. Códigos de Regulación. Disponible en:

http://www.autocontrol.es/pdfs/pdfs_codigos/CODMEDIOAMBIENTE.pdf. REcuperado el día 14

e marzo de 2015

17 Autocontrol. Resoluciones. Disponible en:

http://www.autocontrol.es/panelcontrol/web/paghtml/download.asp?file=rest1335.pdf\&type=rest

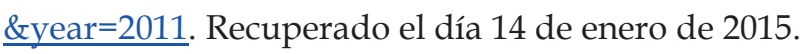


y fácilmente entendibles, deben encontrarse cerca de la aseveración acotada para asegurar que se lean de forma conjunta."

Se trataba de un anuncio publicado en prensa y en la web, donde en la imagen un Honda Accord estaba acompañado de un cuerpo de texto en el cual podía leerse: "Honda Accord Serie Especial (...). Con un motor más respetuoso con el medio ambiente. Y ahora, más a tu alcance que nunca". Debajo se incluye información adicional sobre las prestaciones del coche y las características de la promoción, pero nada que especifique las apelaciones ecológicas realizadas.

Las afirmaciones acerca de la condición ecológica del motor del vehículo promocionado no aportaban las acotaciones necesarias que explicitasen dicha ventaja medioambiental.

El jurado por lo tanto, instó a la marca a la rectificación de la publicidad. A pesar de que Honda es una de las empresas adheridas al Código medioambiental, no acató las disposiciones de Autocontrol, alegando que la notificación llegó cuando la campaña ya había terminado, llevando la rectificación del adjetivo "ecológico" por "eficiente" tan sólo en la web.

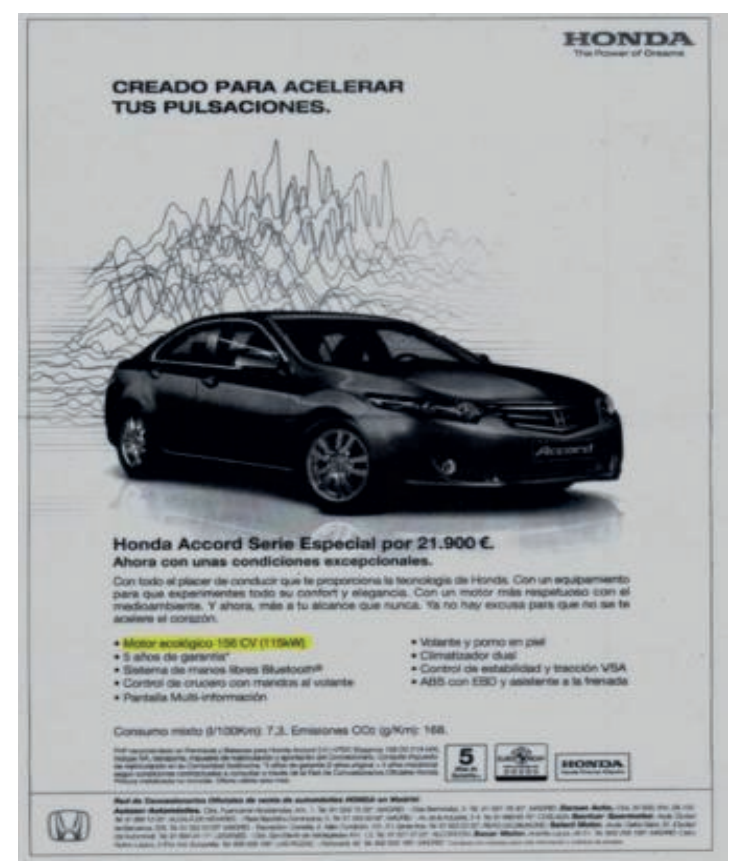

Imagen 7. Anuncio de Honda Accord

La segunda reclamación recibida en Autocontrol llegó de mano de la Asociación de Usuarios de la Comunicación (AUC) contra una publicidad difundida en televisión a nivel nacional de la que era responsable General Motors España, S.L. ${ }^{18}$ Se trata de un anuncio de la marca Opel Corsa, donde el protagonista, un joven urbano, conduce el

18 Autocontrol. Reclamaciones. Disponible en:

http://www.autocontrol.es/panelcontrol/web/paghtml/download.asp?file=rest1347.pdf\&type=rest $\underline{\text { \&year}=2011}$. Recuperado el 21 de septiembre del año 2014 
vehículo por las calles de la ciudad mientras en los edificios comienzan a mostrarse imágenes animadas en sus paredes, en la parte inferior una sobreimpresión ilegible: "El nuevo Opel Corsa ha llegado a tu ciudad. Que empiece el espectáculo. Nuevo Opel Corsa desde 9.600€. Opel. Wir Leben Autos".

El jurado concluyó que la publicidad reclamada infringía la norma 3.3 del Código de Conducta Publicitaria, ya que el scroll que se incluía en el anuncio resultaba completamente ilegible en condiciones normales de visionado, y por las mismas razones la Norma 12 del Código de Autorregulación sobre Argumentos Ambientales en Comunicaciones Comerciales"19: "Si tal información adicional o explicativa se ofrece a través de una sobreimpresión o scroll, se cuidará el tamaño de las indicaciones, el contraste con el fondo, así como en el caso del scroll, su velocidad de paso por pantalla"

Y estas son las dos únicas reclamaciones que ha tramitado Autocontrol, a pesar de las continuas alusiones al medio ambiente a la ecología, a la responsabilidad social con el calentamiento global...

Para prueba un botón: ninguna marca de coche ha eliminado de sus productos la impresiones de logos ECO tal y como exige la Autorregulación del Código de Consolidación de Prácticas Publicitarias y Mercadotecnia de la Cámara Internacional de Comercio:

"Las aseveraciones de naturaleza ambiental pueden hacerse en cualquier medio, incluyendo etiquetado, inserciones en empaques, materiales promocionales y en puntos de venta, literatura del producto, así como vía telefónica, digital o medios electrónicos tales como correo electrónico e Internet. Todos están regulados por este capítulo", "el mensaje comercial no debe contener declaración o imagen alguna que pueda confundir a los consumidores sobre los aspectos o ventajas de tipo ambiental de los productos, ni sobre las acciones que esté llevando a cabo el anunciante en beneficio del medio ambiente...", "las aseveraciones generales de tipo ambiental deben acotarse o evitarse. En especial, aseveraciones tales como "compatible con el medio ambiente" o "ecológicamente seguro", "verde", "sustentable" o cualesquier otra aseveración implicando que un producto o actividad no impacta al ambiente, o sólo lo hace positivamente, no deben hacerse sin la debida acotación, a menos que se cuente con un alto grado de prueba disponible. No debe aseverarse que se ha logrado la sustentabilidad o confirmar que ésta se logró, en tanto no existan métodos generalmente aceptados para medir tales logros..." ${ }^{20 .}$

\subsection{Compensación oculta}

19 Autocontrol. Códigos. 14 de marzo del 2014

http:/ / www.autocontrol.es/pdfs/pdfs_codigos/CODMEDIOAMBIENTE.pdf

20 ICC. Código de Autorregulación Publicitaria. Disponible en :

http://www.iccwbo.org/uploadedFiles/ICC/policy/marketing/Statements/Spanish\%20ICC\%20Co nsolidated\%20Code\%20on\%20MA\%20Practice.pdf. Recuperado el 10 de marzo del 2015. 
Son cada vez más numerosas las empresas que utilizan campañas de responsabilidad social corporativa en las que se apuesta por la causa ambiental, con el único fin de tergiversar la percepción de la marca respecto a las prácticas habituales llevadas a cabo por estas empresas e íntimamente ligadas con la inestabilidad medioambiental.

Mediante estas campañas sociales las empresas esperan lograr un aumento de actitud positiva hacia la marca, minimizando ante el consumidor las consecuencias reales del impacto medioambiental del que son responsables. Las marcas de turismo junto a las de energía han montado, en estos últimos años, su propio carnaval consiguiendo disfrazar a don Carnal de doña Cuaresma.

Una de las causas que pudieran explicar esta situación es la falta de una certificación de sostenibilidad. En la actualidad no existe una certificación universalmente aceptada que permita evaluar la sostenibilidad y con ello, la responsabilidad medioambiental de una empresa. Existen cientos de certificaciones medioambientales que relacionan marca y responsabilidad medioambiental, muchas de ellas creadas por las propias marcas (certificaciones no acotadas ni demostradas) originadas en sus fundaciones. De tal modo que el consumidor debe utilizar sus conocimientos y maestría, llevar a cabo un arduo trabajo de recogida de información para diferenciar una marca sostenible de otra que no lo es. Esto supone eliminar la libertad del consumidor a la hora de elegir la opción más saludable para el medio ambiente, y lo que es más grave, menoscabar la confianza del receptor en las campañas medioambientales, tan necesarias en los últimos años.

Algunas empresas están realizando verdaderos esfuerzos por implantar medidas que refuercen un desarrollo más sostenible, mejoras en la gestión de residuos, la utilización de productos biodegradables, el desarrollo de diseños y construcciones sostenibles que incorporan materiales ecológicos, sistemas de ahorro y energías renovables, la formación de su plantilla y la recuperación de ecosistemas gracias a la reforestación. Estas medidas forman parte de la construcción de la propia imagen de marca y permiten a los receptores contribuir con la sostenibilidad. Receptor, marca y medio ambiente, se ven beneficiados con esta estrategia.

Estas experiencias provechosas pueden verse en peligro ante la habituación del sujeto a reclamos publicitarios medioambientales. Los continuos beneficios medioambientales que ofrecen los mensajes publicitarios provocan la habituación del sujeto y con ello, la reducción de la reactividad ante este valor disminuyendo la probabilidad de respuesta, hecho que se verá reflejado en un cambio de conducta hacia este tipo de estímulos, considerándolos cada vez más irrelevantes. De modo que este tipo de mensajes genera, de un lado irrelevancia, y de otro, desconfianza en virtud de las cuales puede llegar a anteponer barreras psicológicas que impidan analizar correctamente el mensaje y discernir entre el verdadero esfuerzo sostenible y aquel que constituye una falsa promesa. Este hecho pondría en riesgo el interés de algunas marcas por generar imagen verde mediante medidas sostenibles reales, menoscabando el valor social medioambiental, y convirtiendo una ventaja real en un estímulo irrelevante. Hecho que constituiría una grave infracción contra la sociedad en general y contra el individuo en particular. 
Según un estudio realizado por la fundación Empresa \& Clima ${ }^{21}$, la mayoría de consumidores no creen que las empresas apoyen iniciativas ecológicas porque les preocupe en medio ambiente: el $49 \%$ cree que es por cuestiones de marketing o para vender más productos, el $29 \%$ considera que es para mejorar la imagen que la gente tiene de la empresa, sólo un $29 \%$ considera que se debe a una preocupación real por el medio ambiente.

La producción en sí de un automóvil, independientemente de su emisiones contaminantes, junto con la energía consumida (recursos no renovables), hacen casi impensable que este sector lidere iniciativas sostenibles. El automóvil es un auténtico devorador de recursos naturales (el 57\% de la producción mundial de petróleo es utilizado por el transporte terrestre, de los cuales se utiliza aproximadamente la mitad por el coche privado) y es responsable, en gran medida, del efecto invernadero, y aún así: ¿es un sector comprometido con el medio ambiente?

La marca alemana Volkswagen afirmar liderar el primer puesto como la compañía más responsable con el medio ambiente. En su campaña “Think blue" (Imagen 8), intenta presentar sus productos desde una perspectiva más sensible hacia el medio ambiente. Eligen el color azul para romper con la habituación del receptor hacia el color verde, asociándolo también a su marca ambiental "Bluemotion". Según palabras de su director de marketing Luca de $\mathrm{Meo}^{22}$ : “Nuestro objetivo es establecer a 'Think Blue' como una expresión de nuestra mentalidad y actitud a nivel corporativo, y como una característica firme de las actividades ecológicamente sostenibles de la marca Volkswagen. El slogan de 'Think small' simboliza el logro de la marca Volkswagen en la democratización de la movilidad en todo el mundo. El desafío del futuro será lograr movilidad eficiente y sostenible en el mundo. Volkswagen liderará este camino. La campaña expresa este concepto: 'Think small' has become Think Blue."

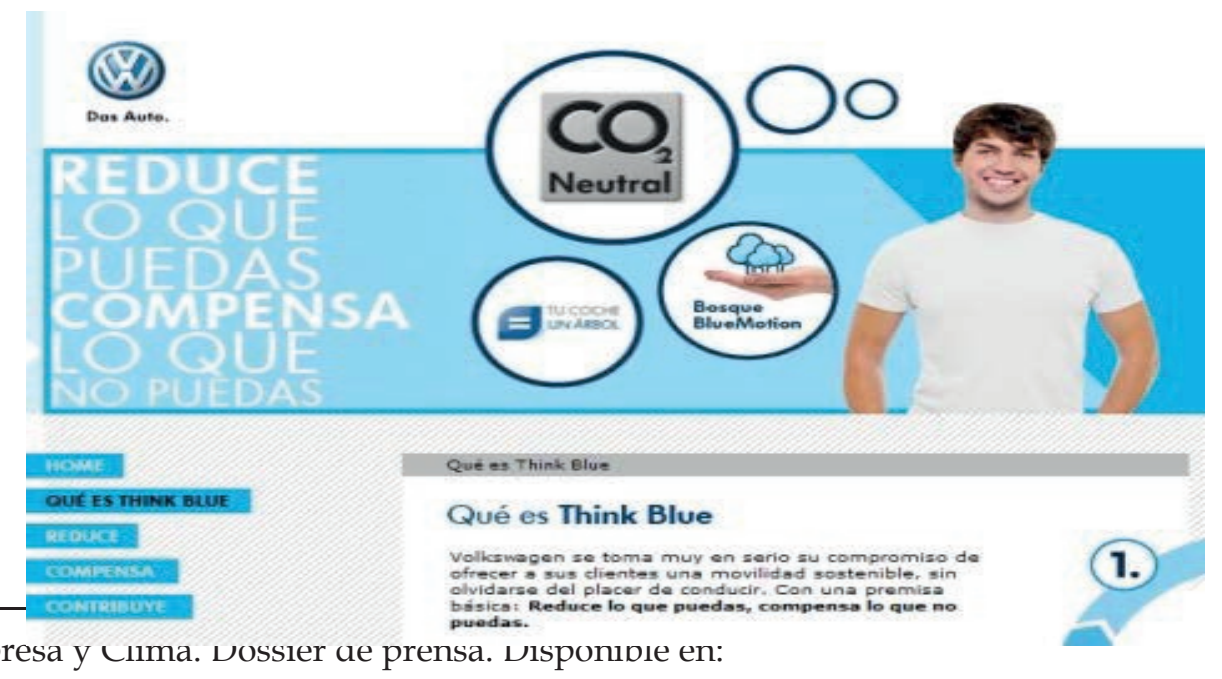

http:/ / www.clubofrome.at/2009/barcelona/p/elviracarles.pdf. Recuperado el 8 de septiembre del 2014.

22 Volkswagen. Sala de comunicación. Luca de Meo. Disponible en:

http://comunicacion.volkswagen.es/actualidad/notas-de-prensa/la-partitura-mas-sostenible-devolkswagen_887-889-c-28301_.html. Recuperado el día 25 de febrero de 2015. 
Imagen 8. Campaña Think blue.

En una reciente campaña asociada a su marca ambiental (Imagen 9) Wolskwagen afirma: En Volkswagen incluimos un equipamiento ecológico en todos nuestros vehículos nuevos: un árbol que se incorpora de serie y que se planta en el bosque BlueMotion para compensar las emisiones de $\mathrm{CO} 2$ de los primeros kilómetros que realices".

Según el dato disponible en la propia web de Volkswagen BlueMotion, plantar un árbol por cada coche vendido supondría absorber alrededor de $300 \mathrm{~kg}$ de CO2 a lo largo de 40 años. Si tenemos en cuenta que $300 \mathrm{~kg}$ son las emisiones que corresponden a unos $2.000 \mathrm{~km}$ en un coche común (que emita $150 \mathrm{~g} / \mathrm{km}$ ) o a unos $1.300 \mathrm{~km}$ en un todoterreno (un simple viaje de ida y vuelta Madrid-Barcelona) ${ }^{23}$, plantar un árbol por coche vendido no saldrá muy rentable a nuestro medio ambiente. De nuevo verdades a medias, beneficios resaltados obtenidos con un discutible menor daño que se convierte en ventaja frente a la competencia. La cuestión es si se respetan los principios de veracidad y de buena fe o se induce a error:

Código General de Conductas Publicitarias, artículo 27 "Campañas con causa social": "27.1.- Cuando en la publicidad se haga referencia a la participación de un anunciante en un acto o campaña benéfica, la publicidad deberá respetar de forma escrupulosa los principios de veracidad y buena fe.

27.2.- Además, deberán observarse las siguientes reglas:

a) El anunciante deberá revelar de forma explícita, inequívoca, y sin inducir a error, el alcance de su participación en el correspondiente acto o campaña benéfica."

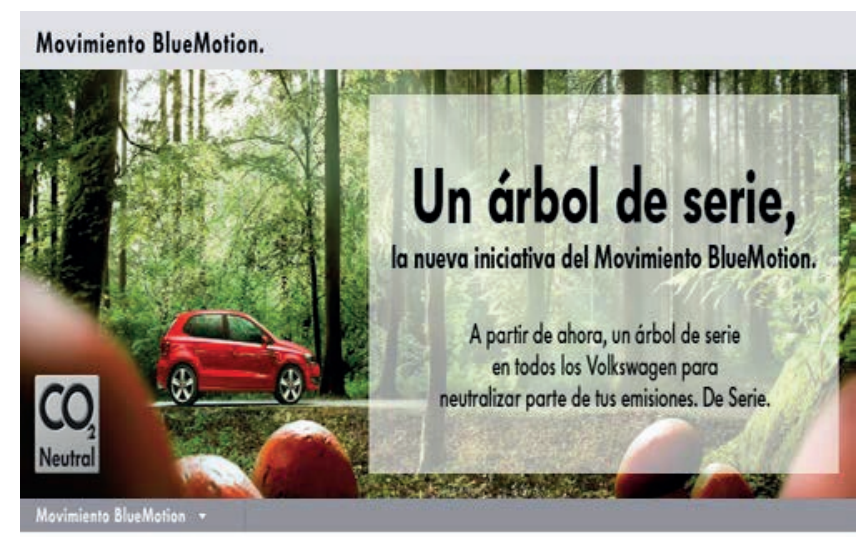

Imagen 9. Campaña Movimiento Blues Motions

23 Blogs El País. Clemente Álvarez. Disponible en: http:/ / blogs.elpais.com/eco-

lab/2010/12/enga\%C3\%B1os-de-la-publicidad-verde/comments/page/5/. Recuperado el día 14 de enero de 2015 
E incluso se atreven a establecer metáforas con claras intenciones moralizantes en sus últimas campañas para promocionar "El nuevo golf ecológico y económico" trasgrediendo de forma clara y explícita todos los códigos de autorregulación nacionales e internacionales. (Imagen 10.)

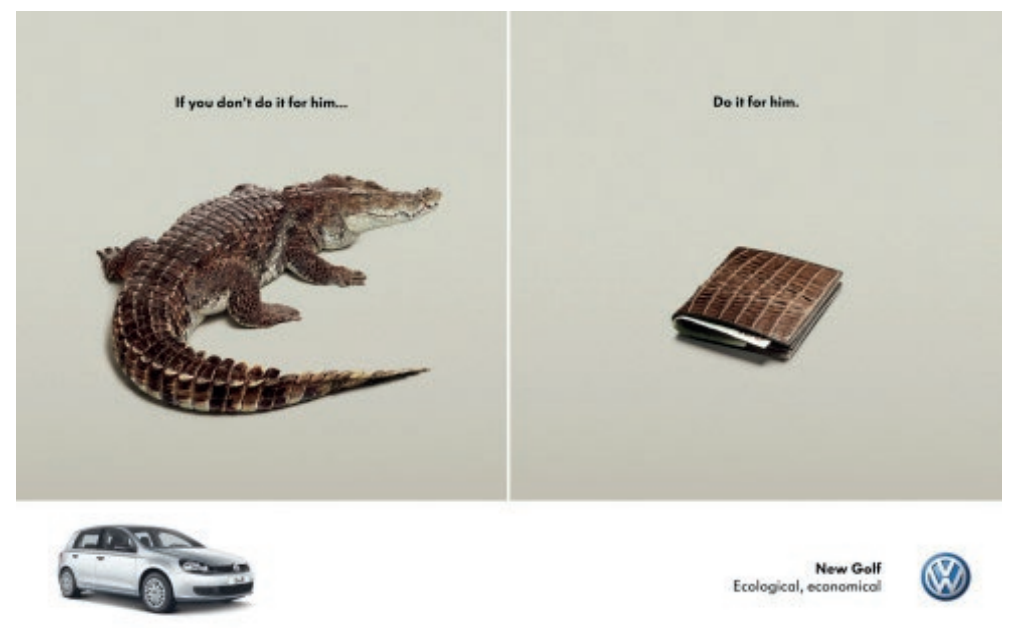

Imagen 10. Campaña de New Golf.

Es evidente que las medias verdades inducen a error al consumidor, la disminución de perjuicios al medio ambiente no puede convertir al producto en un producto ecológico, porque tal y como hemos discutido en párrafos anteriores, esto es poco menos que imposible. Sin embargo, la recepción por parte del sujeto puede llegar a inferir valores de respeto a la naturaleza, compromiso con el medio amiente, valores que serán añadidos a la imagen del producto y de la marca, y cuya inevitable conclusión será: utilizar un vehículo Volkswagen es coherente con el cuidado del medio ambiente.

Similar proyecto desarrolla Toyota (Imagen 11) en colaboración con la Fundación Apadrina Un Árbol. La empresa ofrece al comprar un vehículo de su marca la posibilidad de apadrinar un árbol, en concreto Toyota apadrinó un total de 900 árboles en la Dehesa de Solanillas en la provincia de Guadalajara

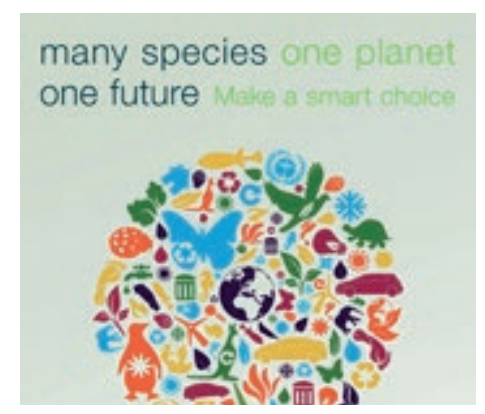


Imagen 11. Campaña Toyota Apadrina un árbol.

Es curioso cómo este tipo de campañas logran generar imagen ecológica produciendo resultados tan curiosos como el encontrado en la página web The independent traveler.com ${ }^{24}$. Esta página oferta operadores de ecoturismo, hoteles ecológicos, vehículos ecológicos, permitiendo a los usuarios, tal y como ellos afirman, reducir la confusión mediante la recopilación de marcas y empresas respetuosas con el medio ambiente, entre ellas: Seat Ecofrieds.

\section{CONCLUSIÓN}

La realidad es que, en muchas ocasiones, estas empresas que se definen como defensoras del medioambiente, invierten mayor presupuesto en publicitar sus aparentes logros sostenibles que en emplear realmente medidas que mejoren la situación medioambiental.

Las reivindicaciones sobre medioambiente, sostenibilidad, ecología... realizadas por este sector llevan a un engaño manifiesto al consumidor, desviando su atención sobre estos supuestas ventajas y dejando a un lado aspectos y atributos que no son nada favorables al medio ambiente.

Esta estrategia de despiste a la cual juega la mayor parte del sector automovilístico, es contraproducente con el esfuerzo que realizan tanto organizaciones no gubernamentales, como organizaciones oficiales, por forzar una conciencia ecológica que nos ayude a llevar una vida más acorde con la sostenibilidad y el cuidado del planeta.

La exaltación del medio ambiente en beneficio propio, y en perjuicio de todos, no parece tener ningún tipo de consecuencias ni social, ni jurídica, ni éticas. Cómo hemos mostrado, las reclamaciones son prácticamente inexistente y las prácticas flagrantemente inmorales. Lo que nos lleva a concluir la autorregulación publicitaria no ha logrado parar el tren verde del sector motor.

\section{REFERENCIAS} 24 Indepent Travel. Disponible en: $\underline{\text { http://www.independenttraveler.com/travel-tips/specialty- }}$
$\underline{\text { travel/green-travel-resources. }}$ Recuperado el día 20 de diciembre de 2014 


\section{Libros Completos}

Inglehasrt, R. (1997) Modernizacion Y Posmodernizacion: El Cambio Cultural, Ecónomico $Y$ Político en 43 Sociedades." Princeton: Princeton University Press.

Fernández-Novoa, C. (1989) Estudios de derecho de la Publicidad. Universidad de Santiago de Compostela. Servicio de publicaciones e intercambio científico. Santiago de Compostela.

Lema Devesa, C. (2007) Problemas jurídicos de la publicidad. Marcial Pons. Madrid.

Patiño Alves, B. (2007) La autorregulación publicitaria: Especial referencia al sistema español. Bosch. Barcelona.

Rodrigo Martín, L. (Coord) (2013) Los maridajes de la publicidad. Las relaciones de la publicidad y otros ámbitos del conocimiento. Icono 14. Estudios de Comunicación. Madrid.

\section{Artículos en papel y electrónicos:}

Autocontrol. Códigos de Regulación. Disponible en:

http://www.autocontrol.es/pdfs/pdfs_codigos/CODMEDIOAMBIENTE.pdf.

REcuperado el día 14 e marzo de 2015

Autocontrol. Resoluciones. Disponible en:

http://www.autocontrol.es/panelcontrol/web/paghtml/download.asp?file=rest133 5.pdf\&type=rest\&year=2011. Recuperado el día 14 de enero de 2015.

Autocontrol. Reclamaciones. Disponible en:

http://www.autocontrol.es/panelcontrol/web/paghtml/download.asp?file=rest134

7.pdf\&type=rest\&year=2011. Recuperado el 21 de septiembre del año 2014

Autocontrol . Códigos. 14 de marzo del 2014

http://www.autocontrol.es/pdfs/pdfs_codigos/CODMEDIOAMBIENTE.pdf Autocontrol . Códigos. 14 de marzo del 2014

http://www.autocontrol.es/pdfs/pdfs_codigos/CODMEDIOAMBIENTE.pdf

Autocontrol. Sentencias. Disponible en:

http://www.autocontrol.es/panelcontrol/web/paghtml/download.asp?file=rest077 4.pdf\&type $=$ rest\&year $=2006$. Recuperado el 17 de marzo de 2015.

Autocontrol. Sentencias. Disponible en:

http://www.autocontrol.es/panelcontrol/web/paghtml/download.asp?file=rest066 2.pdf\&type $=$ rest\&year $=2005$. Recuperado en día 20 de marzo de 2015

Autocontrol. Códigos. Disponible en :

http:// www.autocontrol.es/pdfs/pdfs_codigos/CODMEDIOAMBIENTE.pdf.Consu ltado el día 25 de febrero de 2015

Bigné, E., Andreu, L. y Rodriguez, M. (2000) “Una aproximación a la tipología de la publicidad ecológica”. ESIC Market. N 115, pp. 97-114.

Cámara Internacional de Comercio. Código de Prácticas Publicitarias. Disponible en: http://www.iccwbo.org/uploadedFiles/ICC/policy/marketing/Statements/Spanis h\%20ICC \%20Consolidated \%20Code \%20on\%20MA\%20Practice.pdf. Consultado el 19 de marzo de 2015

Chamorro, A., Miranda, F.J. y Rubio, S. (2006) “El estado de la investigación sobre marketing ecológico en España: Análisis de revistas españolas 1993-2003”. 
Revista Investigaciones Europeas de Dirección y Economía de la Empresa. Vol. 12. No 2. Vigo.

Crane, A. (2000) "Marketing management in an era of shortages". Bussines Horizonts, 17.

El País. Clemente Álvarez. Disponible en: http://blogs.elpais.com/ecolab/2010/12/enga\%C3\%B1os-de-la-publicidad-verde/comments/page/5/.

Recuperado el día 14 de enero de 2015

European Advertising Standards Alliance. Nota de prensa. Disponible en:

http:/ / www.easa-alliance.org/Search/page.aspx/18? sRequest=capitulo\%20E.

Consultado en día 2 de Febrero de 2015.

European Advertising Standards Alliance. Informes 2009. Disponible en

http:// www.easa-alliance.org/Publications/Statistics/page.aspx/375. Consultado

el 20 de diciembre de 2014 Autoncontrol. Códigos. Disponioble en:

http://www.autocontrol.es/pdfs/Cod_conducta_publicitaria.pdf. Recuperado en día 20 de marzo de 2015.

El Kamasutra de la Publicidad. Jepp ¿si?. Disponible en

https://elkamasutradelapublicidad.wordpress.com/2013/09/17/jeepsi/https://elk amasutradelapublicidad.wordpress.com/2013/09/17/jeepsi/. Recuperado el día 12 de enero de 2015.

Fraj, E., Grande, I. y Martínez, E. M. (2002) “Las variables de actitud y de conocimiento como determinantes del comportamiento ecológico". Investigación y Marketing, No 77. pp. 56-66.

Hartmann, P. y Apaolaza Ibáñez, V. (2008) "Virtual nature experiences as emotional benefits in green product consumption: the moderating role of environmental attitudes" Environment and Behavior, Volumen 40 Issue: 6, Pp. 818-842

ICC. Código de Autorregulación Publicitaria. Disponible en :

http://www.iccwbo.org/uploadedFiles/ICC/policy/marketing/Statements/Spanis h\%20ICC\%20Consolidated \%20Code\%20on\%20MA\%20Practice.pdf. Recuperado el 10 de marzo del 2015. Empresa y Clima. Dossier de prensa. Disponible en: http:/ / www.clubofrome.at/2009/barcelona/p/elviracarles.pdf. Recuperado el 8 de septiembre del 2014.

Indepent Travel. Disponible en: http://www.independenttraveler.com/travel-

tips/specialty-travel/green-travel-resources. Recuperado el día 20 de diciembre de 2014

Inglehasrt. R., “Modernización Y Posmodernizacion: El Cambio Cultural, Económico Y Político En 43 Sociedades." Princeton University Press, Princeton, 1997

World Valuessurvey Association. Disponible en :http://www.worldvaluessurvey.org/. Consultado el 30 de Enero de 2015

World Valuessurvey Association. Disponible en: http://www.worldvaluessurvey.org/Upload/5_Soc-Pos-Inf-Post.pdf. consultado el día 30 de enero de 2015

Unión de Consumidores de España. consultado en 12 de enero de 2014, disponible en:

http://www.consumidors.org/UserFiles/File/PDF\%20Altres \%20entittats/Nota\%20 de\%20prensa_Publicidad \%20coches\%20ecologicos.pdf 
RACC Automóvil Club. Dossier de Prensa. Disponible en:

http://imagenes.w3.racc.es/uploads/file/2566_NP_ecotest_fase_1_2003.pdf.

Recuperado el 14 de abril de 2003.

Rodrigo I. y Rodrigo, L. (2013) “La causa social en la creatividad publicitaria”. Pensar la Publicidad. Revista Internacional de investigaciones Publicitarias. Vol. No 2.

Vicente, M. A. y Aguirre, M. S. (2003) “Factores psicológicos determinantes del comportamiento ecológico: una aproximación a través de la evidencia empírica". ESIC Market, No 114, pp. 201-222.

Volkswagen. Sala de comunicación. Luca de Meo. Disponible en:

http://comunicacion.volkswagen.es/actualidad/notas-de-prensa/la-partitura-massostenible-de-volkswagen_887-889-c-28301_.html. Recuperado el día 25 de febrero de 2015.

\section{Autores:}

Marian Núñez Cansado. Licenciada en Ciencias de la Información, Licenciada en Psicología, Doctora en Comunicación y Sociología. Master en Neuropsicología.

Actualmente es profesora de la asignatura; Psicología de la Comunicación y de la asignatura; Ética y Deontología de la Comunicación en la Universidad de Valladolid en el Campus María Zambrano de Segovia, en el grado de Publicidad y Relaciones Públicas.

Profesora del Máster Comunicación con Fines Sociales impartido en la Universidad de Valladolid, Campus de Segovia, de la Asignatura Procesos Psicosociales de la Comunicación publicitaria.

Luis Rodrigo Martín. Licenciado en Publicidad y RR.PP. y Derecho Por la U.C.M., Doctor en Comunicación Audiovisual y Publicidad con Premio Extraordinario de Doctorado por la Universidad de Valladolid. Investigador del G.I.R. Soc-Media de la Universidad Complutense de Madrid y coordinador del grupo de Investigación Tendencias en Publicidad y Consumo de Icono14. Es profesor del Master en Comunicación de las Organizaciones de la Universidad Complutense de Madrid, del Master Investigación de la comunicación como agente Histórico Social de la Universidad de Valladolid y de la Asignatura Procesos de creación del grado de Publicidad y RR.PP. del Campus de Segovia de la Universidad de Valladolid. 